\title{
Peertechz
}

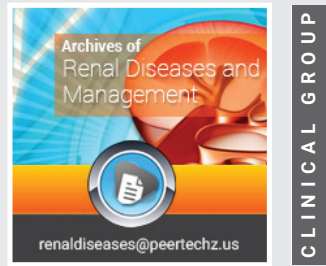

\section{Assessment of quality of life in patients with end stage renal failure using KDQOL-SF}

\author{
Zahid Nadeem ${ }^{1}$, Abdul Bashir ${ }^{2 *}$, Abdul Qadeer ${ }^{2}$, Mirwais \\ $\mathrm{Khan}^{3}$ and Sandal Khan ${ }^{4}$ \\ 'Department of Radiology, Second Affiliated Hospital Xi'an Jiao Tong University Shaanxi, China \\ ${ }^{2}$ Faculty of Pharmacy and Health Sciences, University of Baluchistan, Quetta, Pakistan \\ ${ }^{3}$ Post Graduate Trainee, Anesthesia Department Jinnah Post graduate center, Karachi, Pakistan \\ ${ }^{4}$ Faculty of Pharmacy and Health Sciences University of Balochistan, Quetta
}

Received: 10 December, 2021

Accepted: 30 December, 2021

Published: 31 December, 2021

*Corresponding author: Abdul Bashir, Faculty of Pharmacy and Health Sciences, University of Baluchistan, Quetta, Pakistan, Tel: 03342410934;

E-mail: bukhareeyounas@gmail.com

Copyright License: (c) 2021 Nadeem Z, et al. This is an open-access article distributed under the terms of the Creative Commons Attribution License, which permits unrestricted use, distribution, and reproduction in any medium, provided the original author and source are credited.

Keywords: Health; Quality of life; End stage renal failure; KDQOL-SF survey; Pakistan

https://www.peertechzpublications.com

\section{Check for updates}

\section{Abstract}

Background: Chronic Renal Failure (CRF) is a general health problem having a genuine effect on the quality of life of the patients experiencing hemodialysis.

Objectives: The aim and objectives of this cross-sectional study was to evaluate the effect of dialysis on the quality of life of patients with End Stage Renal Failure (ESRF).

Methodology: Sample of 103 Patients Undergoing hemodialysis were included in study from two hospitals (public sector) of Quetta Pakistan. Information was gathered by the fruition of a self-utilized survey a part of KDQOL-SF fusing the instrument of the SF-36 survey of health and an extra poll so as to incorporate demographics. Writing survey depended on studies, audits and articles got from global information bases concerning the quality of life of individuals with end stage renal failure.

Result: A total of 103 responses were collected out of which 54 (53.4\%) were males and 49 (47.6\%) were females with the mean age between 30 and 45 (38.8\%) years old. Majority of the patients were in a Moderate state of health 56 (54.4\%) and 33(32\%) were those who had Bad health state, while 14 (13.6\%) patients with Good quality of health. Majority of the patients were not at all bothered by dryness of skin (27.2\%), itchy skin (39.8\%), lack of appetite (32\%), washed out or exhausted (39\%), soreness of muscles (35\%), pain in their joints (32\%), easy brouising (45.6\%), sleepiness at the day time (42.7\%), cramps during dialysis (60.2\%) and after dialysis (36.9\%), stiffness of joints (33\%), back pain (31.1\%), numbness in hands or feet (37.9\%), bone aches (30.1\%), muscle pain (41.7\%), headache (26.2\%), stomach problem or nausea $(31.1 \%)$, shortness of breath $(43.7 \%)$, faintness or dizziness $(64.1 \%)$, hot or cold spells $(36.9 \%)$, trouble concentration (52.4\%), trouble in getting breath $(52.4 \%)$, blurred vision (42.7\%), chest pain (52.4\%), swelled ankles (34\%), loss of tast $3(35.9 \%)$, clotting or other access site problems (62.1\%) and majority of the patients were extremely bothered by lack of strength (36.9\%), weakness and fatigue (51.5\%), excessive thirst $(41.7 \%)$, dryness of mouth (34\%), trouble in sleeping (37.9\%), head ach (26.2\%). Majority of the patients were somewhat bothered by high blood pressure (19.4\%) and low blood pressure (13.6\%).

Conclusion: Specific variables, such as age, gender, social support, income, the quality of life of the patients is effected either negatively or positively by education physical functioning health and disease symptoms. Particular factors, for example, age, gender, social support, income, education, physical working wellbeing and ailment side effects can influence either decidedly or adversely the quality of patients life.

\section{Introduction}

Assessment of Quality of Life (QOL) of patients is more and more essential in medical literature [1]. Chronic dialysis therapy allows expanding a patient's life having End-Stage Renal Disease (ESRD). Given that ESRD cannot be cured and dialysis itself has a consequential persuade on the way of life, it is essential to evaluate the State of health of patients in the assessment of renal replacement therapy. Quality of life related to health (QOL) is widely defined as an environmental, mental and communal behavior. Instruments of quality of life evaluate the direct impact of the treatment on the routine lives of patients [2]. Better quality of life scores need to follow better compliance [3] and devaluation of morbidity and mortality [4]. There are many tools to assess the quality of life in patients. Some of the particular tools are epidemicspecific. Kidney Disease Quality of Life Instrument Short Form (KDQOL-SF) has been long-established for the assessment 
of QOL in patients with kidney disorder. It has been adapted into several languages and validate in different origins [5]. A number of studies using KDQOL-SF to evaluate the quality of life in patients dialyzed have latterly been circulated [6]. The use of dialysis to treat end-stage renal failure varies noticeably between regions, apparently in consequence of the differences in demography, the prevalence of end-stage kidney failure [7]. The prevalence of end-stage kidney failure could raise distinctly in the expected decades, by the aging of the community and an increase in the prevalence of diabetes and hypertension Kidney failure patients treated with maintenance dialysis effect a variety of physical and emotional symptoms, commenced a notably high prevalence of depression and the experience of the serious deficiencies in the Quality of Life (QOL) [8]. Symptoms made up of fatigue, pain, muscle cramps, difficulties with sleep and sexual dysfunction affects half or more of patients treated with dialysis [9]. In addition, up to $25 \%$ of patients suffer from depression, and that, in the long-term analysis has been leaded with an increased risk of death [10]. This high load symptoms and depression presumably lead the damage seen in the quality of life within this population [11]. While there is a bit doubt that susceptible patients on reduced maintenance dialysis experience wellbeing, physical and psychological remarkably less is common in the particular areas associated to health in patients with progressive Chronic Renal Insufficiency (CRI) demanding no chronic renal replacement therapy. Understanding the status to whichever symptoms, depression and disorders affect QOL of patients with CKD advanced is essential for two reasons. First of all, ESRD affects nearby 500,000 patients in the United States, CKD is present in at least 20 million Americans, and this estimate is expected to raised with the growing burden of hypertension and diabetes mellitus[12]. Understand the status to whatever the symptoms and depression affect this huge and growing population can help to promote the implementation of symptom alleviating therapies that have a reasonable impact on QOL. Second, characterizing the burden of symptoms and depression and deficiencies in the quality of life to those who are not yet of renal replacement therapy will improve patient and provider to interpret how the particular areas associated to health can reform when leading CKD evolves pointing to the end-stage renal failure. We undertook this survey to correlate the burden of the symptoms, depression and quality of life in patients with Terminal renal failure treated with chronic dialysis and patients with CKD advanced not susceptible on dialysis [13].

\section{Methodology}

A survey of using QOL questionnaire comprising 103 individuals experiencing chronic periodic hemodialysis in two public sector hospitals of Quetta was conducted. Each of the subjects was told that their cooperation was totally deliberate and privacy was guaranteed. Questionnaire was acquired from all of the 103 patients who consented to take an interest.

\section{Inclusion criteria}

Individuals meeting the following criteria were included in the final analysis of this study
- Those receiving chronic hemodialysis treatment.

- 15 years or more of either gender.

- Have no psychiatric disorder.

- Have a palatable altitude of collaboration and perceptual capacity.

\section{Data collection}

A questionnaire consolidating subjective and quantitative methodologies was used for the collection of data. The instrument was made out of two segments, the first concerning demographic data about every respondent. It included 8 questions i.e. age, sex, marital status, residence, cast, level of academic education, working status, monthly income.

The second segment is a part of health related survey SF-36 which was the center of survey KDQOL-SF questionnaire. The feedback form was utilized as a part of the present study was somewhat changed and adjusted with the end goal of this study. It secured personal satisfaction through the measurements of health and the specific instrument in KDQOL-SF, Version 1.3. It included 35 questions about general health, physical functioning, physical role, bodily role, bodily pain, vitality, social functioning, emotional role and mental health. In the fundamental study, patients were requested that rate the degree they were bothered on a 5-point Likert scale from 1 (Not at all bothered) to 5 (Extremely bothered), where higher number showed more severity of the effect of every component on these patients.

\section{Description of research tool}

The SF-36 Health Survey is a popular general tool, that is used in research in general population surveys, in the evaluation in clinical practice and health policies to determine the psychometric properties, in the comparison of the State of health between different groups, different patients and healthy of different categories or between different treatment methods of a group of patients The SF-36 Health Survey is a prevalent general instrument, that is utilized as a part of research, in the assessment in clinical practice and health approaches to determine the psychometric properties, in the correlation of the State of health between various groups, distinctive patients and healthy of various classifications or between various treatment techniques for a gathering of patients [2]. The boundless utilization of the SF-36 in the studies on the quality of life of the overall population or groups of patients makes it a dependable instrument, which has decent unwavering quality and legitimacy. Measurable trial of legitimacy and dependability of the SF - 36 Health Survey, that have been made on an agent test of urban population had positive results [1]. Furthermore, a study directed by the Greeks with respect to the utilization of the KDQOL-SF to measure health quality of life in Greek patients on hemodialysis affirmed the legitimacy and unwavering quality of the Greek interpretation of the short type of the quality of life questionnaire kidney disease (KDQOL $\left.-\mathrm{SF}^{\mathrm{TM}}\right)[3]$. 


\section{Data analysis}

Quantitative data were analyzed using SPSS-V20x86 (Statistical Package for Social Sciences-Version 20). Descriptive statistics, frequencies, tables, and charts were utilized to display the aftereffects of the study.

\section{Results}

Table 1 shows that the all response rate was 103, with $54(53.4 \%)$ males and 49(47.6\%) females. Most of the members were somewhere around 30 and $45(38.8 \%)$ years of age $.84(81.6 \%)$ patients were married, $19(18.4 \%)$ were unmarried. Majority of the patients were Pashtoons 50(48.5\%) from urban areas 58(56.3\%). Educational system of Pakistan consists of primary, middle, metric, intermediate, graduation and post graduation. Majority of the participants were uneducated 53(51.5\%), and $12(11.7 \%)$ patients were metric degree holders. Majority of the participants were housewives $45(43.7 \%)$

Table 1: Sociodemographic of the respondents $(n=103)$

\begin{tabular}{|c|c|c|}
\hline Age group & Frequency & Percent \\
\hline 15 to 30 & 21 & 20.4 \\
\hline 30 to 45 & 40 & 38.8 \\
\hline 45 to 60 & 33 & 32.0 \\
\hline 60 to 75 & 9 & 8.7 \\
\hline \multicolumn{3}{|c|}{ Gender } \\
\hline Male & 54 & 52.4 \\
\hline Female & 49 & 47.6 \\
\hline \multicolumn{3}{|c|}{ Marital status } \\
\hline Married & 84 & 81.6 \\
\hline Unmarried & 19 & 18.4 \\
\hline \multicolumn{3}{|c|}{ Residence } \\
\hline Urban & 58 & 56.3 \\
\hline Rural & 45 & 43.7 \\
\hline \multicolumn{3}{|c|}{ Caste } \\
\hline Pashtoon & 50 & 48.5 \\
\hline Baloch & 24 & 23.3 \\
\hline Panjabi & 19 & 18.4 \\
\hline Sindhi & 1 & 1.0 \\
\hline Other & 9 & 8.7 \\
\hline \multicolumn{3}{|c|}{ Qualification } \\
\hline Religious education & 7 & 6.8 \\
\hline Primary & 9 & 8.7 \\
\hline Middle & 8 & 7.8 \\
\hline Metric & 12 & 11.7 \\
\hline Intermediate & 6 & 5.8 \\
\hline Graduation & 8 & 7.8 \\
\hline Un educated & 53 & 51.5 \\
\hline \multicolumn{3}{|l|}{ Occupation } \\
\hline Un employee & 33 & 32.0 \\
\hline Housewife & 45 & 43.7 \\
\hline Students & 2 & 1.9 \\
\hline Government employ & 9 & 8.7 \\
\hline Own business & 5 & 4.9 \\
\hline Other & 9 & 8.7 \\
\hline \multicolumn{3}{|l|}{ Monthly Income (PKR) } \\
\hline 1000 to 5000 & 4 & 3.9 \\
\hline 5000 to 10000 & 21 & 20.4 \\
\hline 10000 to 20000 & 27 & 26.2 \\
\hline 20000 to 30000 & 5 & 4.9 \\
\hline Above then 30000 & 5 & 4.9 \\
\hline No formal income & 41 & 39.8 \\
\hline
\end{tabular}

therefore majority of patients 41(39.8\%) replied nothing about their income. During the time period of my survey I found more patients under dialysis in sandeman provincial hospital $57(55.3 \%)$.

In Table 2 Majority of the patients were not at all bothered by dryness of skin $28(27.2 \%)$. More respondents were not at all bothered from itchy skin $41(39.8 \%)$. Majority of patients were responded that they have lack of strength and were extremely bothered $38(36.9 \%)$. Majority of respondents were extremely bothered from weakness and fatigue 53(51.5\%). More participants were not at all bothered from lack of apatite $33(32 \%)$. More patients responded that they were not washed out or exhausted $41(39.8 \%)$. Majority of the respondents were not at all bothered from the soreness of muscles 36(36\%). Majority of the patients replied that they were extremely bothered from the excessive thirst at end stage of renal failure $43(41.7 \%)$. More patients were extremely bothered by dryness of mouth 35(34\%). Majority of the patients were not at all bothered by pain in their joints $33(32 \%)$. Majority of participants reported that they have more trouble in sleeping and were extremely bothered $39(37.9 \%)$. Majority of the participants were not at all bothered by easy bruising 47(45.6\%). More patients replied that they have no disorder of sleepiness at day time $44(42.7 \%)$. Majority of the patients were not at all bothered from muscle cramps during dialysis $62(60.2 \%)$ and after dialysis $38(36.9 \%)$. More respondents were not at all bothered by the stiffness of joints 34(33\%). Majority of the patients founded were somewhat bothered from high blood pressure $26(25.2 \%)$ and with low blood pressure $36(35 \%)$. Majority of the patients were not at all bothered from back pain $32(31.1 \%)$, numbness in hands or feet $39(37.9 \%)$, bone aches $31(30.1 \%)$, muscle pain $43(41.7 \%)$, and headache $27(26.2 \%)$, but equal number of patients were also extremely bothered by headache $27(25.2 \%)$. Majority of respondents were not at all bothered from any stomach problem like nausea or upset stomach $32(31.1 \%)$. More patients replied that they have no trouble with memory $48(46.6 \%)$ additionally not at all bothered from shortness of breath 45(43.7\%). More participants responded that they were not at all bothered from faintness or dizziness $66(64.1 \%)$, hot or cold spells $38(36.9 \%)$, trouble concentration $54(52.4 \%)$, trouble in getting breath $54(52.4 \%)$ and more patients reported with no blurred vision $44(42.7 \%)$, with no chest pain 54(52.4\%) having no swelled ankles $35(34 \%)$ and with better taste or not at all bothered from loss of taste $37(35.9 \%)$. Majority of patients had no clotting or other access site problems $64(62.1 \%)$.

In Table 3 health quality score was analyzed and result demonstrates that dominant part of the patients was in Moderate condition of health 56(54.4\%) and 33(32\%) were the individuals who had Bad health state, while $14(13.6 \%)$ patients with Good quality of health. Scoring was done by 36-Item Short Form Survey (SF-36) Scoring Instructions [14]. First, precoded numeric values are recoded per the scoring key. Note that all items are scored so that a high score defines a more favorable health state. In addition, each item is scored on a 0 to 100 range so that the lowest and highest possible scores are 0 and 100, respectively. Scores represent the percentage of total possible score achieved. Then, items in the same scale are averaged 
Table 2: KDQOL-SF dimensions $(n=103)$.

\begin{tabular}{|c|c|c|}
\hline Descriptions & Frequency & Percentage \\
\hline \multicolumn{3}{|l|}{ Dry Skin } \\
\hline Not at all bothered & 28 & 27.2 \\
\hline Somewhat bothered & 23 & 22.3 \\
\hline Moderately bothered & 9 & 8.7 \\
\hline Very much bothered & 19 & 18.4 \\
\hline Extremely bothered & 24 & 23.3 \\
\hline \multicolumn{3}{|l|}{ Itchy Skin } \\
\hline Not at all bothered & 41 & 39.8 \\
\hline Somewhat bothered & 20 & 19.4 \\
\hline Moderately bothered & 8 & 7.8 \\
\hline Very much bothered & 10 & 9.7 \\
\hline Extremely bothered & 24 & 23.3 \\
\hline \multicolumn{3}{|l|}{ Lack of Strength } \\
\hline Not at all bothered & 7 & 6.8 \\
\hline Somewhat bothered & 12 & 11.7 \\
\hline Moderately bothered & 14 & 13.6 \\
\hline Very much bothered & 32 & 31.1 \\
\hline Extremely bothered & 38 & 36.9 \\
\hline \multicolumn{3}{|l|}{ Weakness, Fatigue } \\
\hline Not at all bothered & 6 & 5.8 \\
\hline Somewhat bothered & 12 & 11.7 \\
\hline Moderately bothered & 12 & 11.7 \\
\hline Very much bothered & 20 & 19.4 \\
\hline Extremely bothered & 53 & 51.5 \\
\hline \multicolumn{3}{|l|}{ Lack of appetite } \\
\hline Not at all bothered & 33 & 32.0 \\
\hline Somewhat bothered & 5 & 4.9 \\
\hline Moderately bothered & 14 & 13.6 \\
\hline Very much bothered & 24 & 23.3 \\
\hline Extremely bothered & 27 & 26.2 \\
\hline \multicolumn{3}{|l|}{ Washed out or Drained } \\
\hline Not at all bothered & 41 & 39.8 \\
\hline Somewhat bothered & 35 & 34.0 \\
\hline Moderately bothered & 18 & 17.5 \\
\hline Very much bothered & 9 & 8.7 \\
\hline Extremely bothered & 00 & 00 \\
\hline \multicolumn{3}{|l|}{ Muscle Soreness } \\
\hline Not at all bothered & 36 & 35.0 \\
\hline Somewhat bothered & 21 & 20.4 \\
\hline Moderately bothered & 13 & 12.6 \\
\hline Very much bothered & 17 & 16.5 \\
\hline Extremely bothered & 16 & 15.5 \\
\hline \multicolumn{3}{|l|}{ Excessive thirst } \\
\hline Not at all bothered & 20 & 19.4 \\
\hline Somewhat bothered & 12 & 11.7 \\
\hline Moderately bothered & 11 & 10.7 \\
\hline Very much bothered & 17 & 16.5 \\
\hline Extremely bothered & 43 & 41.7 \\
\hline \multicolumn{3}{|l|}{ Dry mouth } \\
\hline Not at all bothered & 16 & 15.5 \\
\hline Somewhat bothered & 10 & 9.7 \\
\hline Moderately bothered & 14 & 13.6 \\
\hline Very much bothered & 28 & 27.2 \\
\hline Extremely bothered & 35 & 34.0 \\
\hline \multicolumn{3}{|l|}{ Joint pain } \\
\hline Not at all bothered & 33 & 32.0 \\
\hline Somewhat bothered & 13 & 12.6 \\
\hline Moderately bothered & 11 & 10.7 \\
\hline Very much bothered & 19 & 18.4 \\
\hline Extremely bothered & 27 & 26.2 \\
\hline Trouble in sleeping & & \\
\hline
\end{tabular}

Not at all bothered

Somewhat bothered

Moderately bothered

Very much bothered

Extremely bothered

\section{Easy brouising}

Not at all bothered

Somewhat bothered

Moderately bothered

Very much bothered

Extremely bothered

Sleepiness during day

Not at all bothered

Somewhat bothered

Moderately bothered

Very much bothered

Extremely bothered

Cramps during dialysis

Not at all bothered

Somewhat bothered

Moderately bothered

Very much bothered

Extremely bothered

\section{Joint stiffness}

Not at all bothered

Somewhat bothered

Moderately bothered

Very much bothered

Extremely bothered

High blood pressure

Not at all bothered

Somewhat bothered

Moderately bothered

Very much bothered

Extremely bothered

\begin{tabular}{|c|c|}
\hline 38 & 36.9 \\
8 & 7.8 \\
8 & 7.8 \\
10 & 9.7 \\
39 & 37.9 \\
\hline
\end{tabular}

36.9

9.7

37.9

45.6

\begin{tabular}{l|l}
47 & 45.6 \\
17 & 16.5 \\
\hline
\end{tabular}

\begin{tabular}{l|l}
15 & 14.6
\end{tabular}

$17 \quad 16.5$

\begin{tabular}{l|l}
7 & 6.8
\end{tabular}

16.5
6.8

\begin{tabular}{l|l}
\hline 44 & 42.7
\end{tabular}

\begin{tabular}{l|l}
18 & 17.5
\end{tabular}

$15 \quad 14.6$

\begin{tabular}{l|l}
12 & 11.7 \\
14 & 13.6
\end{tabular}

\section{Back pain}

Not at all bothered

Somewhat bothered

Moderately bothered

Very much bothered

Extremely bothered

13.6

umbness in hands or feet

Not at all bothered

Somewhat bothered

Moderately bothered

Very much bothered

Extremely bothered

60.2

\begin{tabular}{c|c}
62 & 60.2 \\
7 & 6.8
\end{tabular}

\begin{tabular}{l|l}
9 & 8.7
\end{tabular}

\begin{tabular}{l|l}
13 & 12.6
\end{tabular}

\begin{tabular}{l|l}
12 & 11.7
\end{tabular}

\section{Bone aches}

Not at all bothered

Somewhat bothered

Moderately bothered

Very much bothered

Extremely bothered

Muscle pain

Not at all bothered

33.0

\begin{tabular}{l|l}
34 & 33.0 \\
21 & 20.4
\end{tabular}

$19 \quad 18.4$

\begin{tabular}{l|l}
20 & 19.4
\end{tabular}

\begin{tabular}{l|l}
9 & 8.7
\end{tabular}

8.7

Somewhat bothered

Moderately bothered

Very much bothered

Extremely bothered

\section{Headaches}

Not at all bothered

Somewhat bothered

Moderately bothered

Very much bothered

Extremely bothered
17.5

25.2

18.4

19.4

19.4

31.1

13.6

14.6

23.3

17.5

\begin{tabular}{l|l}
18 & 17.5 \\
\hline
\end{tabular}

\begin{tabular}{l|l}
\hline 39 & 37.9
\end{tabular}

\begin{tabular}{l|l}
34 & 13.6 \\
\hline
\end{tabular}

\begin{tabular}{l|l}
17 & 16.5
\end{tabular}

22

\begin{tabular}{l|l}
22 & 21.4 \\
11 & 10.7
\end{tabular}

\begin{tabular}{|l|l|}
\hline 31 & 30.1
\end{tabular}

\begin{tabular}{l|l}
31 & 30. \\
20 & 19.4
\end{tabular}

\begin{tabular}{l|l}
18 & 17.5
\end{tabular}

$24-23.3$

\begin{tabular}{c|c}
24 & 23.3 \\
10 & 9.7
\end{tabular}

\begin{tabular}{l|l} 
& \\
\hline 43 & 41.7 \\
24 & 23.3
\end{tabular}

\begin{tabular}{l|l}
24 & 23.3 \\
11 & 10.7 \\
\hline 16 & 15.5
\end{tabular}

\begin{tabular}{l|l}
9 & 8.7
\end{tabular}

\begin{tabular}{l|r} 
& \\
\hline 27 & 26.2
\end{tabular}

\begin{tabular}{l|l}
27 & 26.2 \\
21 & 20.4
\end{tabular}

\begin{tabular}{r|r}
21 & 20.4 \\
9 & 8.7
\end{tabular}

\begin{tabular}{c|c}
\hline & 8.7 \\
19 & 18.4
\end{tabular}

\begin{tabular}{l|l}
197 & 26.2 \\
\hline
\end{tabular}

\begin{tabular}{l|l}
16 & 15.5
\end{tabular}

Citation: Nadeem Z, Bashir A, Qadeer A, Khan M, Khan S (2021) Assessment of quality of life in patients with end stage renal failure using KDQOL-SF. Arch Renal Dis Manag 6(1): 015-022. DOI: https://dx.doi.org/10.17352/2455-5495.000037 
Nausea or upset stomach

Not at all bothered

Somewhat bothered

Moderately bothered

Very much bothered

Extremely bothered

Low blood pressure

Not at all bothered

Somewhat bothered

Moderately bothered

Very much bothered

Extremely bothered

Trouble with memory

Not at all bothered

Somewhat bothered

Moderately bothered

Very much bothered

Extremely bothered

Shortness of breath

Not at all bothered

Somewhat bothered

Moderately bothered

Very much bothered

Extremely bothered

Cramps after dialysis

Not at all bothered

Somewhat bothered

Moderately bothered

Very much bothered

Extremely bothered

Faintness or dizziness

Not at all bothered

Somewhat bothered

Moderately bothered

Very much bothered

Extremely bothered

Hot or cold spells

Not at all bothered

Somewhat bothered

Moderately bothered

Very much bothered

Extremely bothered

Trouble concentration

Not at all bothered

Somewhat bothered

Moderately bothered

Very much bothered

Extremely bothered

Trouble getting breath

Not at all bothered

Somewhat bothered

Moderately bothered

Very much bothered

Extremely bothered

\section{Blurred vision}

Not at all bothered

Somewhat bothered

Moderately bothered

Very much bothered

Extremely bothered

\section{Chest pain}

Not at all bothered

Somewhat bothered

Moderately bothered

Very much bothered

Extremely bothered

\begin{tabular}{|c|c|c|}
\hline Swelling of ankles & & 34.0 \\
\hline Not at all bothered & 35 & 20.4 \\
Somewhat bothered & 21 & 18.4 \\
Moderately bothered & 19 & 14.6 \\
Very much bothered & 15 & 12.6 \\
Extremely bothered & 13 & \\
\hline Loss of taste & & 35.9 \\
\hline Not at all bothered & 37 & 10.7 \\
Somewhat bothered & 11 & 11.7 \\
Moderately bothered & 12 & 10.7 \\
Very much bothered & 11 & 31.1 \\
Extremely bothered & 32 & \\
\hline or other access site problems & & 62.1 \\
Not at all bothered & 64 & 18.4 \\
Somewhat bothered & 19 & 11.7 \\
Moderately bothered & 12 & 6.8 \\
Very much bothered & 7 & 1.0 \\
Extremely bothered & 1 &
\end{tabular}

Table 3: Health status of patients with end stage renal failure.

\begin{tabular}{|c|c|c|}
\hline Health Status & $\begin{array}{c}\text { Frequency } \\
\mathbf{n = 1 0 3}\end{array}$ & Percent \\
\hline Good Health & 14 & 13.6 \\
\hline Moderate Health & 56 & 54.4 \\
\hline Poor health & 33 & 32.0 \\
\hline
\end{tabular}

together to create the 8 scale scores. Items that are left blank (missing data) are not taken into account when calculating the scale scores. Hence, scale scores represent the average for all items in the scale that the respondent answered [14].

According to Table 4 mean comparison of the individual demo-graphs were taken and is calculated and determining of $\mathrm{p}$-value have been done which shows that $\mathrm{p}$-values of Gender $(p=0.693)$, Residence $(p=0.237)$ and Hospital $(p=0.324)$ compared are exceeding than 0.05 which has no significance over the quality of life of patient. While Age group, marital status, cast, qualification, occupation, monthly income have significance over the quality of life, and are less than <0.05. Other than there is no significance over quality of life.

\section{Discussion}

In this study, renal failure negatively affected the quality of patients' life, influencing their psychological health, their physical capacity, and in addition their personal life. Numerous patients as a rule leave their occupation, their family or their home because of long-haul treatment since they must be near to the dialysis centre or they might be hospitalized for some days. Concerning their interpersonal connections, these patients are aggressive, on edge and apprehensive to their carers and to the staff who provide them the appropriate care. The analysis of the KDQOL-SF scale demonstrated that a considerable lot of the members perceived renal failure as a substantial burden in their life and they trusted that nephropathy influenced adversely their lives. This takes after from the way that a portion of the respondents were feeling disappointed, while some were regularly feeling disturbed attempting to adapt to their disease. In an exploration survey, concerning depression in patients with $\mathrm{CRF}, 60 \%$ of the members were feeling 
Table 4: Comparison of mean Health score.

\begin{tabular}{|c|c|c|c|}
\hline Age group & $\begin{array}{c}\text { Frequency } \\
n=103\end{array}$ & Mean \pm SD & Significant $p$-Value \\
\hline 15 to 30 & 21 & $2.00+0.548$ & \multirow{4}{*}{$<0.001$} \\
\hline 30 to 45 & 40 & $2.32+0.694$ & \\
\hline 45 to 60 & 33 & $2.24+0.614$ & \\
\hline 60 to 75 & 9 & $1.78+0.667$ & \\
\hline \multicolumn{4}{|c|}{ Gender } \\
\hline Male & 54 & $2.06+0.627$ & 0.693 \\
\hline Female & 49 & $2.33+0.653$ & \\
\hline \multicolumn{4}{|c|}{ Marital status } \\
\hline Married & 84 & $2.24+0.652$ & $<0.001$ \\
\hline Unmarried & 19 & $1.95+0.621$ & \\
\hline \multicolumn{4}{|c|}{ Residence } \\
\hline Urban & 58 & $2.16+0.721$ & 0.237 \\
\hline Rural & 45 & $2.22+0.560$ & \\
\hline \multicolumn{4}{|c|}{ Caste } \\
\hline Pashtoon & 50 & $2.10+0.614$ & \multirow{5}{*}{$<0.001$} \\
\hline Baloch & 24 & $2.50+0.590$ & \\
\hline Panjabi & 19 & $2.11+0.737$ & \\
\hline Sindhi & 1 & $2.00+.000$ & \\
\hline Other & 9 & $2.00+0.707$ & \\
\hline \multicolumn{4}{|c|}{ Qualification } \\
\hline Religious education & 7 & $1.86+0.690$ & \multirow{7}{*}{$<0.001$} \\
\hline Primary & 9 & $2.44+0.527$ & \\
\hline Middle & 8 & $1.88+0.354$ & \\
\hline Metric & 12 & $1.92+0.793$ & \\
\hline Intermediate & 6 & $1.67+0.516$ & \\
\hline Graduation & 8 & $2.50+0.535$ & \\
\hline \multirow[t]{2}{*}{ Un educated } & 53 & $2.30+0.638$ & \\
\hline & $\begin{array}{c}\text { Frequency } \\
n=103\end{array}$ & Mean \pm SD & $\begin{array}{l}\text { Significant } \\
\text { p-Value }\end{array}$ \\
\hline \multicolumn{4}{|c|}{ Occupation } \\
\hline Un employee & 33 & $2.12+0.650$ & \multirow{6}{*}{$<0.001$} \\
\hline Housewife & 45 & $2.36+0.645$ & \\
\hline Students & 2 & $2.00+0.000$ & \\
\hline Government employ & 9 & $2.22+0.441$ & \\
\hline Own business & 5 & $2.00+0.000$ & \\
\hline Other & 9 & $1.67+0.866$ & \\
\hline \multicolumn{4}{|c|}{ Monthly income (in PKR) } \\
\hline 1000 to 5000 & 4 & $1.50+0.577$ & \multirow{6}{*}{$<0.001$} \\
\hline 5000 to 10000 & 21 & $2.29+0.717$ & \\
\hline 10000 to 20000 & 27 & $2.30+0.669$ & \\
\hline 20000 to 30000 & 5 & $1.80+0.447$ & \\
\hline Above then 30000 & 5 & $2.20+0.587$ & \\
\hline No formal income & 41 & $2.17+0.587$ & \\
\hline
\end{tabular}

disappointed, since they were not as functional as they were before the start of dialysis [15]. As per another study, the time spent on dialysis was among the five most elevated appraised stressors for the members. This is on the grounds that the greater part of the patients, get hemodialysis three times each week and the larger part of them burn through four hours for every dialysis session. This indicates roughly 12 hours a week for dialysis, which is a lot of time for these patients [16].

Concerning anxiety because of their kidney failure, an expansive rate of patients $(50.5 \%)(n=48)$ had direct to anxiety. The most regular reasons for stress are the fear of imminent death and the instability about what's to come [17] and in addition their fear of the likelihood that their Arteriovenous fistula will get to be non-functional [18]. Also, a huge stressor for patients on dialysis is the possibility of getting infected, the entanglements of the illness and their physical health [19]. Concerning physical functioning of the patients, men had higher scores (higher levels of quality of life) contrasted with women who demonstrated factually huge ( $p$ 0.693) for those aged between 30 to 45 years. Because of their physical health, the vast majority of the members are compelled to reduce the time spent on routine activities, to perform fewer activities than they might want and to play out their exercises less precisely. The disability of physical strength is likewise brought about by the physical pain experienced in every dialysis session and the day after dialysis.

The results of the present study demonstrated that increasing the members did not encounter any physical pain like pain in their joints (32\%), back pain $(31.1 \%)$, bone aches $(30.1 \%)$, muscle pain $(41.7 \%)$, and headache $27(26.2 \%)$, chest pain $(52.4 \%)$, while some of them were to an extremely bothered from headache $27(26.2 \%)$. This demonstrates physical pain does not have any significant impact on the quality of their life, while the diminishment of pain might be because of the utilization of cut materials of advanced technology and the specialization of health experts in pain treatment. These discoveries diverge from those of a past study, where pain was the most regular side effect, which brought on significant issue in the quality of life and emotional, social and economic disturbances to patients getting dialysis [20].

It ought to be noticed that patients getting dialysis don't as a rule have muscle pain $(41.7 \%)$, cramps during $(60.2 \%)$ and after $(36.9 \%)$ dialysis, dizziness or faintness $(64.1 \%)$, lack of appetite (32\%), numbness of hands $(37.9 \%)$, nausea and stomach upsets $(31.1 \%)$,. As an aftereffect of this, the above indications don't more often than not cause stress to these patients. This might be because of the ampleness of dialysis which is accomplished by all mechanical and medical advances in the field of dialysis, and patients' consistence with the proper eating regimen which should be low in phosphorus [16]. Concentrate additionally demonstrates that dialysis can likewise bring about a few signs and symptoms like lack of strength, fatigue, weakness and excessive thirst, dry mouth, trouble in sleeping, hypertension which extremely bothered the quality of life of patients.

With respect to limitations of ESRF, liquid and nourishment confinement is a major source of stress for these patients. The results of the present study concur with those of a past research concentrate on, where liquid and food restrictions were the most stressful factors for the patients [16]. Excessive thirst extremely bothered more patients $43(41.7 \%)$, it should be focused on that consistence with liquid limitation is especially difficult during hot times of the year, when patients have an increased thirst [21].

Likewise, most of the members had a diminished limit with respect to work in this study, which bothered them a lot. A past research think about directed by Kaitelidou et al, 23 had similar results, where $39.4 \%$ of the respondents reported that the disease kept them from having the capacity to work. Also, examine presents that more patients were unemployed or housewife females $45(43.7 \%)$ unemployment is connected with 
physical and psychological problems of patients, for example, anxiety, depression, sexual dysfunction and loss of self-esteem [22]. According to result of study monthly income of majority of the patients were answered as nothing $41(39.8 \%)$. In the meantime, the diminished capacity to work prompts to social and financial changes in patients' lives, with the loss of income and crumbling of their living [23].

With respect to level of academic education, $7(6.8 \%)$ of the patients had religious education, $9(8.7 \%)$ had completed primary school, $8(7.8 \%)$ middle, $12(11.7 \%)$ metric, $6(5.8 \%)$ intermediate, and $8(7.8 \%)$ were graduated. Also, 53(51.5\%) were found uneducated. The results of this study demonstrate that the relationship between the level of academic education and the quality of life is statistically significant. All the more particularly, individuals with more elevated amount of academic education have higher level of quality of life. This is because that individuals with more have higher level of academic education may have quality in their daily life, good health, good job, participation in leisure activities and a comfortable standard of living that gives them satisfaction and health [24]. Majority of the patients had moderate state of health 56(54.4\%). The appropriate training of patients before the start of dialysis helps them to pick viably the treatment methodology of renal replacement therapy they will take after. Moreover, it helps patients to keep on working after the start of dialysis. Also, health experts with the appropriate training can adequately advise patients keeping in mind the end goal to defer ailment movement and keep some other different extra problems.

\section{Conclusion and recommendation}

The impact of the symptoms of end-stage renal failure on the quality of life of patients, the frequency of the periodic dialysis, the consistence of patients with the treatment regimen and the antagonistic impacts of the malady on patients are the most elevated fixation rates, influencing fundamentally the measurement of physical and psychosocial health. The dialysis procedure itself, education, age and sexual orientation seem to influence the capacity of patients to work and psychosocial health disorder, which unfavorably influences their quality of life related to their health. The writing alludes to the significance and the need of socialization, education and psychological support of patients, their families and relatives, as per the requirements of patients. In the meantime, one needs reassessment of the methodology of all helpful and strong for the most ideal social and mental support of patients experiencing hemodialysis. Assessment, consolation and support of human services experts are to urge patients to acknowledge the limits of the illness and its treatment and to empower them to attempt their self-care support with responsibility. Besides, the health care providers and advancement of health projects concerning patients with Chronic Renal Failure ought to improve their certainty and concentrate on emotional health issues that distress them (i.e. depression, tension and suicide ideation). In the meantime, guiding projects would be exceptionally valuable for the staff of dialysis units, since they would raise their mindfulness and advance their biopsychosocial approach towards patients.

\section{Limitation of the study}

In the present study, the outcomes can't be summed up to the whole number of patients with kidney disease in light of the fact that the patients involved a little clinical specimen. Another limitation of this study is the way that there may not be trust in self-reports of patients about their problems, particularly their economic and psychological problems and some those are uneducated and can't compose or read the apparatus or survey of the study, hence the specialist filled those questionnaires by his own written work taking after the answers of the patient. There is a need for further examination of the exploration topic at a bigger specimen of patients with chronic renal failure.

\section{References}

1. Valderrábano F, Jofre R, López-Gómez JM (2001) Quality of life in end-stage renal disease patients. Am J Kidney Dis 38: 443-464. Link: https://bit.ly/3FH4q7E

2. Korevaar JC, Jansen MA, Merkus MP, Dekker FW, Boeschoten EW, et al. (2000) Quality of life in predialysis end-stage renal disease patients at the initiation of dialysis therapy. The NECOSAD Study Group. Perit Dial Int 20: 69-75. Link: https://bit.ly/3EGLiFF

3. DeOreo PB (1997) Hemodialysis patient-assessed functional health status predicts continued survival, hospitalization, and dialysis-attendance compliance. Am J Kidney Dis 30: 204-212. Link: https://bit.ly/3HIIWPc

4. Mapes DL, Lopes AA, Satayathum S, McCullough KP, Goodkin DA, et al. (2003) Health-related quality of life as a predictor of mortality and hospitalization: the Dialysis Outcomes and Practice Patterns Study (DOPPS). Kidney Int 64: 339 349. Link: https://bit.ly/3JtZRj9

5. Ware JE, Sherbourne CD (1992) The MOS 36-item short-form health survey (SF-36): I. Conceptual framework and item selection. Med Care 30: 473-483. Link: https://bit.ly/3ESm5YZ

6. Ibrahim S, El Salamony O (2008) Depression, quality of life and malnutritioninflammation scores in hemodialysis patients. Am J Nephrol 28: 784-791. Link: https://bit.ly/3FW5dBX

7. Collins AJ, Foley RN, Chavers B, Everson S, Eggers P,et al. (2011) US Renal Data System, USRDS 2011 Annual Data Report: Atlas of Chronic Kidney Disease and End-Stage Renal Disease in the United States. National Institute of Diabetes and Digestive and Kidney Diseases 10.

8. Davison SN, Jhangri GS (2005) The impact of chronic pain on depression, sleep, and the desire to withdraw from dialysis in hemodialysis patients. $J$ Pain Symptom Manage 30: 465-473. Link: https://bit.ly/3HhYNgo

9. Weisbord SD, Fried LF, Arnold RM, Fine MJ, Levenson DJ, et al. (2005) Prevalence, severity, and importance of physical and emotional symptoms in chronic hemodialysis patients. J Am Soc Nephrol 16: 2487-2494. Link: https://bit.ly/3HmMa3L

10. Kimmel PL, Peterson RA, Weihs KL, Simmens SJ, Alleyne S, et al. (2000) Multiple measurements of depression predict mortality in a longitudinal study of chronic hemodialysis outpatients. Kidney Int 57: 2093-2098. Link: https://bit.ly/3FHyekA

11. Merkus MP, Jager KJ, Dekker FW, de Haan RJ, Boeschoten EW, et al. (1999) Physical symptoms and quality of life in patients on chronic dialysis: results of The Netherlands Cooperative Study on Adequacy of Dialysis (NECOSAD). Nephrol Dial Transplant 14: 1163-1170. Link: https://bit.ly/3exLpst

12. Coresh J, Selvin E, Stevens LA, Manzi J, Kusek JW, et al. (2007) Prevalence of chronic kidney disease in the United States. JAMA 298: 2038-2047. Link: https://bit.ly/3zeYf8y

Citation: Nadeem Z, Bashir A, Qadeer A, Khan M, Khan S (2021) Assessment of quality of life in patients with end stage renal failure using KDQOL-SF. Arch Rena Dis Manag 6(1): 015-022. DOI: https://dx.doi.org/10.17352/2455-5495.000037 
13. Abdel-Kader K, Unruh ML, Weisbord SD (2009) Symptom burden, depression, and quality of life in chronic and end-stage kidney disease. Clin J Am Soc Nephrol 4: 1057-1064. Link: https://bit.ly/3qv3AV8

14. Health R (2016) 36-Item Short Form Survey (SF-36) Scoring Instructions. Link: https://bit.ly/3zeS447

15. Gerogianni SK, Babatsikou FP (2014) Psychological Aspects in Chronic Renal Fail. Health Science Journal 8. Link: https://bit.ly/3Hkx3YI

16. Gerogianni K (2003) Stressors of patients undergoing chronic hemodialysis Nursing 42: 228-246.

17. Spyrou A (2004) Stress in chronic dialysis patients, Thesis, 2004

18. Joachim K (2002) Quality of life of persons with chronic renal failure, Thesis.
19. Papadakis E (2010) Approach of patients with kidney disease and patients with beta-thalassemia in a general hospital in crete and investigation of their quality of life.

20. Balodimos C, Petropoulou H, Triantafyllou G (2006) The treatment of chronic pain in patients with hemodialysis. Dialysis Living 15: 6-12.

21. Gabriel J (2010) A patient's guide to dialysis and transplantation2012: Springer Science \& Business Media.

22. Muehrer RJ, Schatell D, Witten B, Gangnon R, Becker BN, et al. (2011) Factors affecting employment at initiation of dialysis. Clin J Am Soc Nephrol 6: 489496. Link: https://bit.ly/3HmMijL

23. Stavrianou K (2007) Technology assessment of home dialysis study of factors affecting adoption and evaluation of quality of life of hemodialysis patients in Greece. Thesis.
Discever a bigger Lepaet and Vistbility of your artiche palieation with

Peertechx Publications

\section{HighNights}

- Spnalsry publinef af Oincio

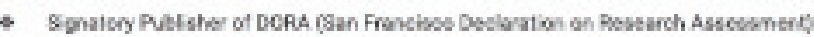

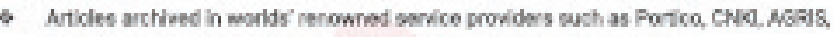

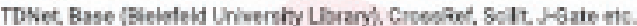

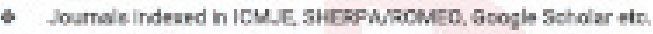

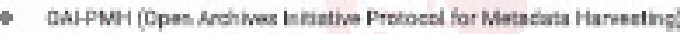

- Dedicated Eahoris Baurd foe every joumd

- Asturate and rapid peer review prostss

- hereosad etobiens of putishad articles trough sronobiens

- Reduoed tmelhe for anticle pibloation

Sutmot pour artiles and exparlance a now arge in patikation serwlees

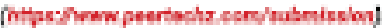

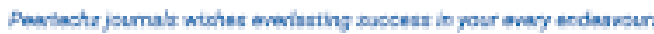

